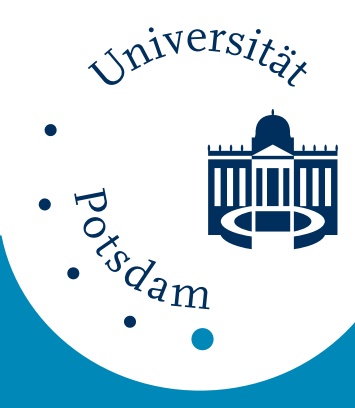

\title{
Universität Potsdam
}

C. A. D. de Kort, Martin G. Peter, A. B. Koopmanschap

Binding and degradation of juvenile hormone III by haemolymph proteins of the Colorado potato beetle: A re-examination

first published in:

Insect Biochemistry. - 13 (1983), 5, pp. 481 - 487

ISSN 0020-1790

DOI 10.1016/0020-1790(83)90005-7

Postprint published at the Institutional Repository of the

Potsdam University:

In: Postprints der Universität Potsdam :

Mathematisch-Naturwissenschaftliche Reihe ; 68

http://opus.kobv.de/ubp/volltexte/2008/1677/

http://nbn-resolving.de/urn:nbn:de:kobv:517-opus-16777

Postprints der Universität Potsdam

Mathematisch-Naturwissenschaftliche Reihe ; 68 


\title{
BINDING AND DEGRADATION OF JUVENILE HORMONE III BY HAEMOLYMPH PROTEINS OF THE COLORADO POTATO BEETLE: A RE-EXAMINATION
}

\author{
C. A. D. DE Kort, M. G. Peter* and A. B. Koopmanschap \\ Laboratory of Entomology, Agricultural University, P.O. Box. 8031, $6700 \mathrm{EH}$ Wageningen, \\ The Netherlands and \\ *Institute für Organische Chemie und Biochemie der Rheinischen Friedrich-Wilhelms-Universität Bonn, \\ Gerhard-Domagk-Str. 1, D-5300 Bonn, West Germany
}

\begin{abstract}
The haemolymph of the adult Colorado potato beetle, Lepinotarsa decemlineata Say, contains a high molecular weight $(\mathrm{MW}>200,000) \mathrm{JH}$-III specific binding protein. The $K_{\mathrm{d}}$ value of the protein for racemic $\mathrm{JH}$-III is $1.3 \pm 0.2 \times 10^{-7} \mathrm{M}$. It has a lower affinity for racemic JH-I and it does not bind JH-III-diol or JH-III-acid. The binding protein does discriminate between the enantiomers of synthetic, racemic JH-III as was determined by stereochemical anaysis of the bound and the free JH-III. Incubation of racemic JH-III with crude haemolymph results in preferential formation of (10S)-JH-III-acid, the unnatural configuration. The JH-esterase present in $L$. decemlineata haemolymph is not enantioselective. It is concluded that the most important function of the binding protein is that of a specific carrier, protecting the natural hormone against degradation by esterases. The carrier does not protect JH-I as efficiently as the lower homologue.
\end{abstract}

Key Word Index: Juvenile hormone, Leptinotarsa decemlineata, JH-III-specific carrier protein, enantioselectivity

\section{INTRODUCTION}

The titre of juvenile hormone $(\mathrm{JH})$ in insect haemolymph is an equilibrium between its rate of synthesis/release by the corpora allata and its rate of uptake, degradation and excretion. In addition, during circulation in the haemolymph, JH may be degraded by carboxylesterases or bind to specific or unspecific proteins or to the body wall or tissue membranes (for review see: de Kort and Granger, 1981).

Two classes of haemolymph proteins have been identified as binding proteins in Lepidopteran insects: low-affinity high molecular weight lipoproteins and high-affinity low molecular weight proteins (Kramer et al., 1976; Peterson et al., 1982). Studies with $\left[10-{ }^{3} \mathrm{H}\right] \mathrm{JH}-\mathrm{I}$ revealed the presence of a high molecular weight lipoprotein with low-affinity for JH-I $\left(K_{\mathrm{d}} \sim 10^{-5} \mathrm{M}\right)$ in haemolymph of Leptinotarsa decemlineata (Kramer and de Kort, 1978). Recently, experiments have shown that the Colorado beetle haemolymph contains only JH-III (de Kort et al., 1982).

Indeed the observation that JH-I displayed a low rate of protection against the high levels of $\mathrm{JH}$ specific esterases known to occur in haemolymph of the Colorado potato beetle (de Kort et al., 1978, 1979) may be due to the fact that this is not the naturally occurring $\mathrm{JH}$ in the beetle. In addition, the natural (10R)-enantiomers bind with high specificity to haemolymph binding proteins (Goodman et al., 1978; Schooley et al., 1978; Peter et al., 1979a).

Thus, many uncertainties remained concerning the identity and function of $\mathrm{JH}$ binding proteins in the Colorado potato beetle. This study re-examines the occurrence and function of $\mathrm{JH}$ binding proteins in the haemolymph of this insect, using racemic tritiated JH-III and JH-I.

\section{MATERIALS AND METHODS}

\section{Chemicals}

Racemic (2E,6E,10-cis)-diastereomer of JH-I was purchased from Calbiochem, and racemic (2E,6E)-diastereomer of JH-III from Fluka. Radiolabelled racemic substrates $\left[10^{3} \mathrm{H}\right] \mathrm{JH}-\mathrm{I}$ and $\left[10^{-3} \mathrm{H}\right] \mathrm{JH}-\mathrm{III}$ (spec. act. 13.0 and $11.6 \mathrm{Ci} /$ mmol resp.) were from NEN-Chemicals. Materials and equipment for chromatography are described below in context with the appropriate procedures. All chemicals and solvents used were of highest available purity and purchased from various commercial sources. Deionized water was purified by pumping through a Lowbar RP-8 column (size B, Merck), which was regenerated at regular intervals by washing with methanol.

\section{Insects}

Larvae and adults of the Colorado potato beetle, Leptinotarsa decemlineata Say, were reared at $25^{\circ} \mathrm{C}$ on fresh potato foliage (de Kort, 1969). Two photoregimes were employed: long-day ( $18 \mathrm{~h}$ photophase), which leads to reproduction or short-day ( $10 \mathrm{~h}$ photophase), which results in diapause ten to 12 days after adult emergence. Haemolymph from 4-day old males and females was collected in capillary pipettes after clipping the wings or hindlegs. After removal of the haemocytes by centrifugation $(10,000 \mathrm{~g}$ for $5 \mathrm{~min}$ at $4^{\circ} \mathrm{C}$ ) the pooled haemolymph samples were stored at $-20^{\circ} \mathrm{C}$ until use.

\section{Gel permeation chromatography}

Haemolymph samples $(200 \mu \mathrm{l})$ were chromatographed at $4^{\circ} \mathrm{C}$ on a $1.6 \times 100 \mathrm{~cm}$ column packed with Biogel A $5 \mathrm{~m}$ (BioRad-Laboratories). The elution buffer, containing $0.15 \mathrm{M} \mathrm{KCl}$ and $0.05 \mathrm{M}$ potassium phosphate-buffer $\mathrm{pH} 7.2$, was controlled at a flow-rate of $10 \mathrm{ml} / \mathrm{h}$ by a LKB 2132 microperpex peristaltic pump and the absorbance of the 
eluate was monitored continuously at $280 \mathrm{~nm}$ using a LKB 2138 Uvicord S. Fractions ( $2.5 \mathrm{ml}$ each) were collected with a LKB Ultrorac fraction collector.

Prior to column chromatography, haemolymph samples were incubated at 4 or $20^{\circ} \mathrm{C}$ for $1 \mathrm{~h}$ with $10^{-7} \mathrm{M}$ $\left[10^{3} \mathrm{H}\right] \mathrm{JH}-\mathrm{III}$, containing $1.5 \times 10^{6} \mathrm{dpm}$. For measurement of the radioactivity $1.0 \mathrm{ml}$ from each column fraction was counted in $10 \mathrm{ml}$ Aqualuma (Lumac), using a Searle Mark III liquid scintillation counter.

For identification of the radioactive components, appropriate fractions were pooled, extracted three times with ethylacetate. Evaporation was followed by thin-layer chromatography according to Weaver et al. (1980). The position of $\mathbf{J H}$ and $\mathbf{J H}$-acid was delineated under u.v. light after addition of unlabelled markers. The appropriate regions of the plate were scraped off and counted by liquid scintillation counting (counting efficiency $40-45_{0}^{\circ}$ )

\section{Kinetics of $\mathrm{JH}$ degradation}

Incubations were carried out in Pyrex centrifuge tubes coated with polyethyleneglycol (PEG). Since we had many difficulties in getting reproducible results with $\mathrm{PEG}$-coating, we describe the coating procedure in detail. Tubes were filled with PEG (mol. wt 20,000) solutions 1 or $4 \%(w / v)$ in distilled water for $1 \mathrm{~h}$. After the solutions were decanted the tubes were dried upside down at $20^{\circ} \mathrm{C}$ overnight. The tubes were not rinsed with water after coating.

Appropriate amounts of labelled racemic $\left[10^{-3} \mathrm{H}\right] \mathrm{JH}-\mathrm{I}$ or $\left[10-{ }^{3} \mathrm{H}\right] \mathrm{JH}-$ III $\left(1.5 \times 10^{6} \mathrm{dpm}\right)$ were added to the coated tubes in ethanolic solutions. After evaporation of the ethanol, $150 \mu$ l potassium phosphate buffer $0.05 \mathrm{M}$ pH 7.2 also containing $0.15 \mathrm{M} \mathrm{KCl}$ were added and the tubes were incubated at $4 \mathrm{C}$ for $1 \mathrm{~h}$ to dissolve $\mathrm{JH}$. The final concentrations of $\mathrm{JH}$ in the incubations were $2 \times 10^{-7} \mathrm{M}$, which is the physiological concentration in long-day beetles (de Kort et al., 1982). The concentration of $\mathrm{JH}$ in ethanolic solution was checked spectroscopically at $220 \mathrm{~nm}(c=13,800$; Peter and Dahm, 1975)

After $\mathrm{JH}$ was dissolved in the buffer, $150 \mu \mathrm{l}$ haemolymph was added and rapidly mixed with a Vortex-mixer. The tubes were incubated at $25^{\circ} \mathrm{C}$ and after appropriate times $25 \mu \mathrm{l}$ samples were taken in duplicate and immediately added to $1.0 \mathrm{ml}$ ethyl acetate. After addition of $0.5 \mathrm{ml}$ distilled water, the organic phase was separated from the water phase by centrifugation $(2000 \mathrm{~g}$ for $10 \mathrm{~min}$ ). The wate phase was extracted three times more with $1.0 \mathrm{ml}$ ethyl acetate. After evaporation of ethyl acetate under nitrogen the extracts were separated on silica-gel plates as described above. The zones with $\mathrm{JH}$ and $\mathrm{JH}$-acid were scraped from the plates and counted separately by liquid scintillation.

\section{Binding assay with PEG}

In these experiments $4 \%$ PEG coated borosilicate tubes (Corning $10 \times 40 \mathrm{~mm}$ ) were used. To these tubes $100 \mu$ TMK buffer $(0.010 \mathrm{M}$ Tris $-\mathrm{HCl} \mathrm{pH} 7.40 .15 \mathrm{M} \mathrm{KCl}$ and $5 \mathrm{mM} \mathrm{MgIl}$ ) and $8000 \mathrm{dpm}\left[10-{ }^{3} \mathbf{H}\right] \mathrm{JH}-\mathrm{III}$ dissolved in $5 \mu 1$ ethanol were added. Subsequently a $1: 1$ dilution series of unlabelled JH-III or JH-I was made in ethanol in the range of $10^{-4}$ to $10^{-7} \mathrm{M}$. From these dilutions $5 \mu \mathrm{l}$ samples were added to the tubes, mixed and kept in ice for one hour. Each concentration was tested in duplicate.

Haemolymph esterases were inhibited by pre-incubation with $10^{-4} \mathrm{M}$ paraoxon for $1 \mathrm{~h}$ at $0 \mathrm{C}$ and subsequently diluted with TMK-buffer, fortified with $5 \mathrm{mg} / \mathrm{ml} \gamma$-globulin and $6 \times 10^{-4} \mathrm{M}$ PMSF (phenylmethylsulphonylfluoride). From these samples of diluted blood $100 \mu$ l were added to the tubes and thoroughly mixed. After incubation at $0^{\circ} \mathrm{C}$ for i h the hormone-protein complex was precipitated by addition of $300 \mu 1$ PEG (mol. wt 6000) according to Koeppe et al. (1981). After centrifugation, $(4000 \mathrm{~g}$ for $10 \mathrm{~min})$, the supernatants were removed by suction and the pellets dissolved in $50 \mu 10.5 \mathrm{M} \mathrm{NaOH}$ and counted as described above. Preliminary experiments revealed that the associ- ation of $\left[10-{ }^{3} \mathrm{H}\right] \mathrm{JH}-\mathrm{IHI}$ with haemolymph proteins is extremely rapid, reaching equilibrium within five $\mathrm{min}$

In the experiments using JH-III-diol. JH-III was con verted to the diol according to the method of Strambi $2 t a l$. (1981). The product was separated by TLC and dissolved in ethanol.

\section{Stereochemical analysis}

The procedures employed in the configurational assay were with some minor improvements the same as described previously (Peter et al.. 1979a: 1981). Routinely, $200 \mu \mathrm{g}$ of unlabelled carrier $\mathrm{JH}$ or $\mathrm{JH}$-acid were added to the samples. JH-acids were converted into $\mathbf{J H}$ by means of diazomethane in diethyl ether. Transformation into the corresponding JH-diols (radiochemical yield: $84-89^{\circ}$ ) was performed by acid catalyzed hydration; tetrahydrofuran: $0.14^{\circ}$, perchloric acid $(1: 1, v / v ; 2 \mathrm{~h}: 20 \mathrm{C})$ as described elsewhere (Peter and Dahm, 1975). Acylation of the diols with $(+)-R-\alpha$-methoxy- $x$-trifluoromethylphenylacetic acid chloride (MTPA-Cl) $(20 \mu \mathrm{l}$ in $100 \mu \mathrm{l}$ dry pyridine; $2 \mathrm{~h} ; 20 \mathrm{C}$ ) was followed by evaporation of the reaction mixture under dry nitrogen, addition of $100 \mu \mathrm{g}$ acetone-2,4-dinitrophenylhydrazone and $100 \mu \mathrm{g}$ nonanal-2,4-dinitrophenyl hydrazone in $100 \mu 1$ benezene. The mixture was extracted three times with $0.5 \mathrm{~mol}$ toluene and the extracts applied to a SepPakSilica cartridge (Waters). The MTPA derivatives of the JH were eluted together with the yellow coloured marker dyes with $10 \mathrm{~m}$ ! hexanc-ethyl acetate $(3: 1$, viv). Rotary evaporation was followed by thin layer chromatography on at $0.5 \mathrm{~mm} \times 20 \mathrm{~cm} \times 20 \mathrm{~cm}$ silica gel plate with benzene ethyl acetate $(17: 3, v / v)$. The radiochemical yield at this stage was $75-98^{\circ}$ from the diols. The diastereomeric MTPAderivatives were finally separated on a $0.4 \times 31 \mathrm{~cm} \mu$-porasil column (Waters) with $n$-hexane ethyl acetate-2-propanol (91:9:0.03. by vol.) at a flow rate of $1.5 \mathrm{ml} \cdot \mathrm{min}$. The eluate was monitored with a Waters Model 440 u.v.-detector at a wavelength of $254 \mathrm{~nm}$. These conditions allow baseline resolution of the MTPA-diastereomers of JH-I and of JH-III in less than $30 \mathrm{~min}$ (cf. Hamnett et al. 1981). Recovery of radioactivity was $>90^{\%}$. Fractions of $0.75 \mathrm{ml}$ were collected and assayed for radioactivity by liquid scintillation counting after mixing with $4 \mathrm{ml}$ Aqualuma cock tail.

\section{RESULTS}

Figure 1 illustrates the elution pattern of haemolymph proteins of the Colorado potato beetle after separation on Biogel A $5 \mathrm{~m}$. Paraoxon treated $\left(10^{-4} \mathrm{M}\right)$ or untreated haemolymph was incubated with $10^{-7} \mathrm{M}\left[10-{ }^{3} \mathrm{H}\right] \mathrm{JH}-\mathrm{III}$ at $4 \mathrm{C}$ during $1 \mathrm{~h}$ and subsequently applied to the column. After $20 \mathrm{~h}$ elution, the amount of radioactivity recovered ranged between 82 and $97^{\circ} \%$. With paraoxon treated haemolymph $85 \%$ of the radioactivity eluted in fractions $35-46$, together with high-molecular weight proteins (Fig. 1). With untreated haemolymph two-thirds of the radioactivity eluted between fractions 62-71 (Fig. 1). Analysis by TLC of the radioactivity containing fractions revealed that fractions $35-46$ contained undegraded JH-III, whereas fractions 62-71 contained JH-III-acid. These results lead to the following conclusions: (1) JH-III is effectively bound to highmolecular weight haemolymph proteins of the Colorado potato beetle, whereas JH-III-acid is not. (2) $\mathrm{A}$ significant portion of bound $\mathbf{J H}-\mathrm{III}$ is not degraded by haemolymph esterases.

Even if we incubated untreated blood for one hour at $20^{\circ} \mathrm{C}$ with $\left[10-{ }^{3} \mathrm{H}\right] \mathrm{JH}-\mathrm{III}$ prior to column chromatography, more than $20^{\circ}$ of the labelled JH-III was recovered in fractions $35-46$. 


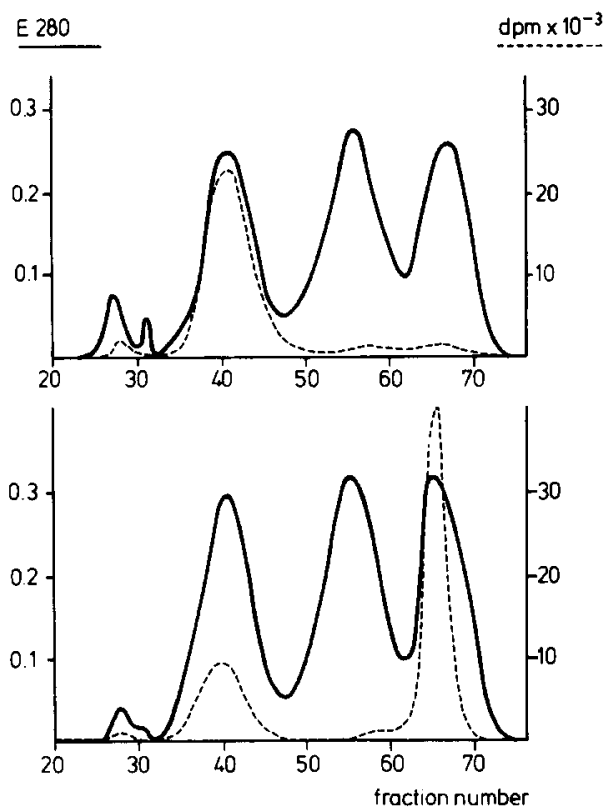

Fig. 1. Column chromatographic separation of Colorado beetle haemolymph on Biogel A $5 \mathrm{~m}$. Upper graph: haemolymph treated with $10^{-4} \mathrm{M}$ paraoxon. Lower graph: untreated haemolymph. Straight line: absorbancy at $280 \mathrm{~nm}$. Dotted line: radioactivity.

When commercial $\left[10-{ }^{3} \mathrm{H}\right] \mathrm{JH}-\mathrm{III}$, a racemic mix ture of (10R)- and (10S)-enantiomers, is incubated with insect haemolymph, the (10R)-enantiomer binds more specifically with the binding proteins than the (10S)-enantiomer (Schooley et al., 1978; Peter et al., 1979a). We therefore decided to determine the stereochemical identity of the $\mathrm{JH}$ and $\mathrm{JH}$-acid present in the fractions after gel-chromatography. The results are summarized in Table 1. The bound JH-III consists mainly of the natural (10R)-enantiomer, whereas JH-III-acid was mainly composed of the unnatural (10S)-enantiomer.

Similar experiments using $\left[10-{ }^{3} \mathrm{H}\right] \mathrm{JH}-\mathrm{I}$ yielded low quantities of undegraded JH-I, suggesting that JH-I is degraded faster than JH-III by Colorado beetle haemolymph. We therefore investigated the kinetics of degradation of both $\mathrm{JH}$ homologues by 1:1 diluted haemolymph derived from 4-day old long-day beetles. The results are illustrated in Fig. 2. JH-I was degraded faster than JH-III in four different experiments. Moreover, the kinetics of degradation did not follow a straight line when plotted logarithmically (Fig. 2). The biphasic line may suggest that the unnatural enantiomer is degraded faster than the natural enantiomer. To study this possibility $\left[10-{ }^{3} \mathrm{H}\right] \mathrm{JH}-\mathrm{I}$ and $\left[10-{ }^{3} \mathrm{H}\right] \mathrm{JH}-\mathrm{III}$ were incubated with haemolymph until $50 \%$ of the hormones were degraded. This took 5 and $20 \mathrm{~min}$ respectively for JH-I and JH-III. The incubations were rapidly stopped by
$\%$ undegraded $\mathrm{JH}$

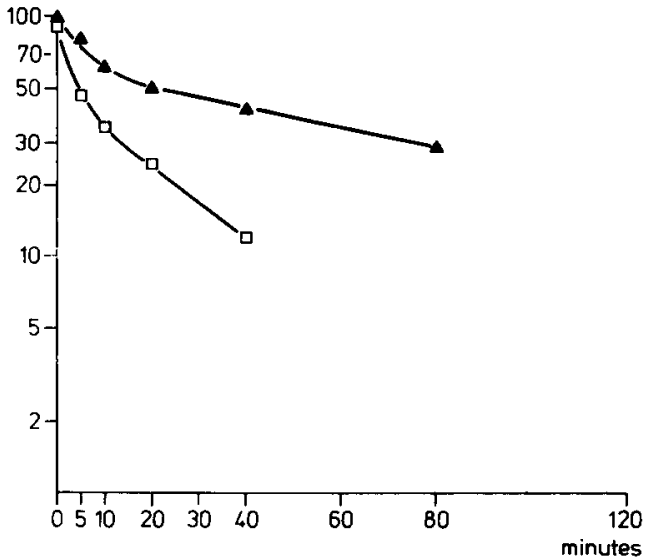

Fig. 2. Kinetics of degradation of racemic JH-I and JH-III as a function of time in 1:1 diluted haemolymph of the Colarado potato beetle. Symbols: squares: JH-I, triangles: JH-III. The variation in the percentages undegraded JH ranged between 1.9 and $4.0 \%$ in four different experiments.

adding ethylacetate and the lipid fractions extracted and separated by TLC. Subsequently JH and JH-acid were subjected to stereoanalysis. The results are summarized in Table 2 . The undegraded hormone fractions of both JH-I and JH-III showed an excess of the natural (10R)-enantiomers, whereas the $\mathrm{JH}$ acid fractions of both homologues are mainly composed of the unnatural (10S)-enantiomers.

Next, the time course of hydrolysis was determined in a 1:20 (v/v) diluted haemolymph sample with $10^{-7} \mathrm{M}\left[10-{ }^{3} \mathrm{H}\right] \mathrm{JH}-\mathrm{III}$. Under these conditions, hydrolysis of JH-III is much faster than in concentrated haemolymph. Within $15 \mathrm{~min}$, less than $30 \%$ and after 40 min less than $10 \%$ of the hormone remains unchanged. This result suggests that the JH-esterase is not enantioselective. Therefore, the enantioselectivity observed in more concentrated haemolymph most likely results from protection of the natural enantiomer of JH-III by the binding protein.

Subsequently, the characteristics of the JH-binding protein were studied. To separate bound from free hormone, PEG-precipitation was used (Koeppe et al., 1981) instead of activated charcoal adsorption (Kramer and de Kort, 1978). First the relationship between the amount of haemolymph and the per-

Table 2. Distribution of radioactivity in MTPA-derivatives prepared from $\mathrm{JH}$ and $\mathrm{JH}$-acid after $50 \%$ degradation in $1: 1$ diluted haemolymph

\begin{tabular}{lcccc}
\hline & \multicolumn{2}{c}{ JH } & \multicolumn{2}{c}{ JH-acid } \\
& $\% 10 \mathrm{R}$ & $\%$ 10S & $\%$ 10R & $\%$ 10S \\
\hline JH-I & 78.1 & 21.9 & 24.6 & 75.4 \\
JH-III & 84.7 & 15.3 & 26.2 & 73.8 \\
\hline
\end{tabular}

Table 1. Distribution of radioactivity in MTPA-diastereomers prepared from JH-III and JH-III-acid after separation of bound and unbound radioactivity on Biogel A $5 \mathrm{~m}$

\begin{tabular}{rccccccc}
\hline & Total dpm & \multicolumn{2}{c}{ JH-III } & \multicolumn{2}{c}{ Total dpm } & \multicolumn{2}{c}{ JH-III-acid } \\
in JH-III & $\%$ loR & $\% 10 \mathrm{~S}$ & in JH-acid & $\%$ & $10 \mathrm{R}$ & $\%$ & $10 \mathrm{~S}$ \\
\hline $4^{\circ} \mathrm{C}$ & 100,040 & 85.0 & 15.0 & 126,880 & 22.3 & 77.7 \\
$20^{\circ} \mathrm{C}$ & 73,600 & 95.9 & 4.1 & 187,680 & 46.0 & 54.0 \\
\hline
\end{tabular}




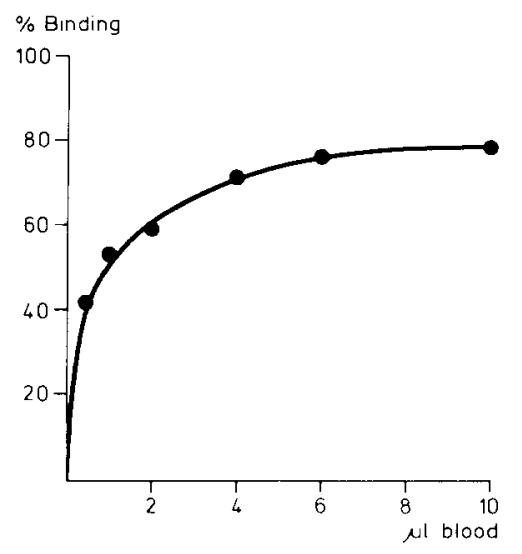

Fig. 3. Relation between the amount of haemolymph and the percentage binding of racemic $\left[10-{ }^{3} \mathrm{H}\right] \mathrm{JH}-\mathrm{III}$. The incubation mixture consisted of $200 \mu \mathrm{l}$ of TMK-buffer, $8000 \mathrm{dpm}$ of $\left[10-{ }^{3} \mathrm{H}\right] \mathrm{JH}-\mathrm{III}$ and increasing amounts of paraoxon-treated haemolymph from 4-day old short-day beetles. Each point represents the mean of a duplicate experiment. The differences in the duplicates ranged between 0.2 and $2.7^{\circ}$.

centage of binding was studied at a $\mathrm{JH}$-concentration of $10^{-9} \mathrm{M}$. As shown in Fig. 3, very small amounts of haemolymph can effectively bind $\left[10-{ }^{3} \mathrm{H}\right] \mathrm{JH}-\mathrm{III}$. Equivalents of $1 \mu 1$ haemolymph in a total volume of $200 \mu \mathrm{l}$ buffer solution binds about $50 \%$ of racemic $\left[10-{ }^{3} \mathrm{H}\right] \mathrm{JH}-\mathrm{III}$. This amount of haemolymph was subsequently used in the following competition studies. To minimize interference with endogenous $\mathrm{JH}-\mathrm{III}$ at the binding sites, we decided to use blood from short-day beetles, which are known to contain thirty times lower JH-III titres (de Kort et al., 1982). The results of the assay are given in a Scatchard-plot (Fig. 4). From this graph a dissociation constant of $1.3 \pm 0.2 \times 10^{-7} \mathrm{M}$ can be calculated for racemic JH-III. A similar experiment using long-day blood yielded a $K_{\mathrm{d}}=1.6 \times 10^{-7} \mathrm{M}$.

To check binding specificity, competitive displacement experiments were carried out with $\mathrm{JH}-\mathrm{I}$ and JH-III-diol. The results are given in Fig. 5. Racemic $\mathrm{JH}-\mathrm{I}$ does not compete as effectively as JH-III for the $\left[10-{ }^{3} \mathrm{H}\right] \mathrm{JH}-\mathrm{III}$ binding sites, whereas JH-III-diol shows no displacement of $\mathrm{JH}-\mathrm{III}$ in the concentration range tested.

Finally, enantioselectivity of the binding protein was investigated by the following experimental series: racemic $\left[10-{ }^{3} \mathrm{H}\right] \mathrm{JH}-\mathrm{III}$ was equilibrated with $5 \mu \mathrm{l}$ paraoxon treated haemolymph in $1.0 \mathrm{ml}$ buffer at $\mathrm{JH}$ concentration $1.7 \times 10^{-9} \mathrm{M}$ and $2.2 \times 10^{-7} \mathrm{M}$, each in duplicate. After separation of the bound and free

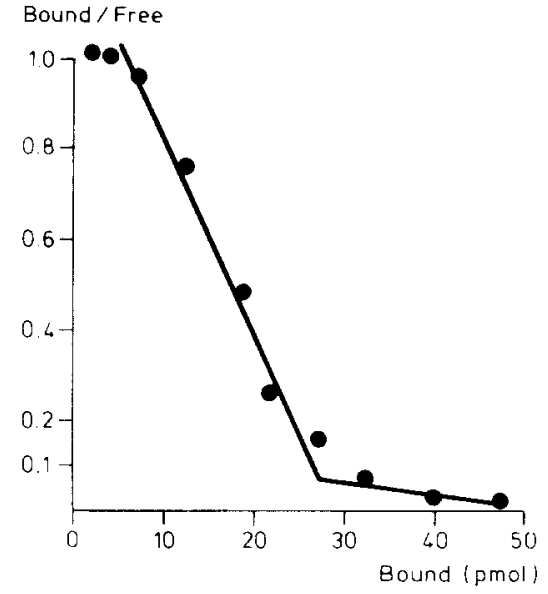

Fig. 4. Scatchard-plot analysis of $\left[10-{ }^{3} \mathrm{H}\right] \mathrm{JH}-\mathrm{III}$ binding to haemolymph from 4-day old short-day beetles. The incubation mixture consisted of $200 \mu 1$ of TMK-buffer, $\mid \mu 1$ of paraoxon-treated haemolymph, $8000 \mathrm{dpm}$ of $\left[10{ }^{-3} \mathrm{H}\right] \mathrm{JH}-\mathrm{III}$ and increasing amounts of unlabelled racemic JH-III. Each point represents the mean of a duplicate experiment and has been repeated three times, resulting in an average $K_{\mathrm{d}}$ of

$$
1.3 \pm 0.2 \times 10^{-7} \mathrm{M}
$$

hormone by means of precipitation with $\mathrm{PEG}$, both fractions were extracted and the $\mathrm{JH}$ subjected to the derivatization procedure to yield the MTPAdiastereomers. The results of the configurational assay are given in Table 3 . At a $\mathrm{JH}-\mathrm{III}$ concentration $1.7 \times 10^{-9} \mathrm{M}$, the degree of enantioselectivity is

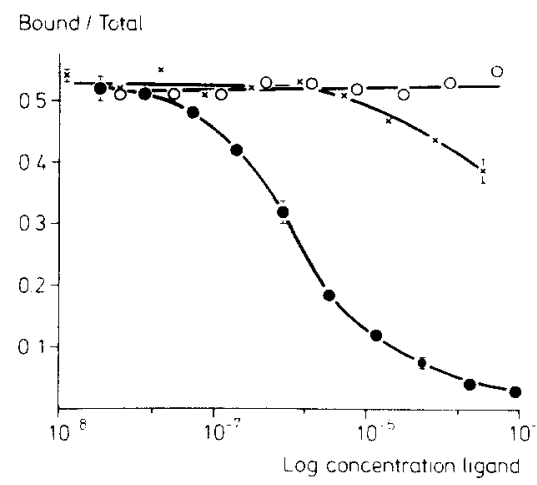

Fig. 5. Competitive displacement of $\left[10-{ }^{3} \mathrm{H}\right] \mathrm{JH}-\mathrm{III}$ from Colorado beetle haemolymph by JH-III $(\mathcal{O}), \mathrm{JH}-\mathrm{I}(x)$, and JH-III-diol $(O)$. Incubation mixture is the same as in Fig. 4 , except that racemic mixtures of unlabelled JH-I, JH-III and $\mathbf{J H}$-III-diol were used. The points represent the mean from four (JH-I and JH-III) or two experiments (JH-IIIdiol) respectively. The SD values are indicated by bars.

Table 3. Distribution of radioactivity in MTPA-diastereomers derived from [10- $\left.{ }^{3} \mathrm{H}\right] \mathrm{JH}-\mathrm{III}$ in the binding assay

\begin{tabular}{cccccc}
\hline $\begin{array}{c}\text { Substrate } \\
\text { concentration } \\
(\mathrm{M})\end{array}$ & $\begin{array}{c}\text { MTPA-derivative from } \\
\text { Of racemate } \\
\text { bound }\end{array}$ & \multicolumn{2}{c}{ bound JH-III } & \multicolumn{2}{c}{ Free JH-III } \\
$1.7 \times 10^{4}$ & 68.5 & 53.6 & 46.4 & 11.5 & 88.5 \\
$1.7 \times 10^{-9}$ & 64.7 & 69.6 & 30.4 & 12.6 & 87.5 \\
$2.2 \times 10^{7}$ & 56.5 & 72.3 & 27.7 & 14.9 & 86.1 \\
$2.2 \times 10^{7}$ & 58.9 & 73.5 & 26.5 & 15.9 & 84.1 \\
\hline
\end{tabular}

The experiment has been carried out in duplicate. The results of both experiments have been illustrated. 
rather low when the bound fraction is evaluated. The unbound hormone, however, consists of a significant excess of the unnaturally configurated enantiomer. The enantioselectivity of the binding sites is much more clearly visible at a substrate concentration of $2.2 \times 10^{-7} \mathrm{M}$, where the bound fraction shows an excess of the (10R)-(natural)-enantiomer whereas the unbound hormone in fact is mostly the unnatural (10S)-enantiomer with high optical purity (see Discussion). These data prove the preferential binding of the natural enantiomer of JH-III.

\section{DISCUSSION}

Earlier studies have shown that the haemolymph of the Colorado potato beetle contains very high "JHspecific" esterase activity (de Kort et al., 1978; 1979). Considering the rather high titres of JH-III in longday animals (de Kort et al., 1982), the existence of highly active $\mathrm{JH}$ degrading enzyme(s) presents a logical problem towards the understanding of the actually observed hormone titres. Usually, degradation of $\mathrm{JH}$ in insect haemolymph is experimentally determined by measuring the relative amount of $\mathrm{JH}$-acid formed from racemic $\mathrm{JH}$. Half lives of the hormones in haemolymph or tissues are then usually determined from degradation rates after less than $50 \%$ substrate consumption. These procedures in fact do not evaluate the possibility that, due to enantioselective interactions of either esterases or binding proteins with the racemic JH-substrate, degradation of preferentially one enantiomer may be observed. This, in the extreme, may lead to erroneous conclusions with respect to the persistence of the hormone under physiological conditions. An enantioselective process can only be excluded with safety, when the conversion of a racemic substrate follows a linear time course on a logarithmic scale up to complete substrate consumption, provided that the initial substrate concentration is $\leqslant 2 \mathrm{Km}$. Following the discovery that in haemolyph of Locusta migratoria hydrolysis of JH-III occurs preferentially on the unnatural enantiomer (Peter et al., 1979a), it appeared necessary to re-investigate the degradation of JH-III in the Colorado beetle, paying attention especially to the stereochemical identity of undegraded substrate as well as of the products of enzyme catalyzed reactions. The methodology of the configurational assay employed in the present study is based on well established procedures. Due to recent comments regarding suspected difficulties associated with the derivatization procedure (Feyereisen et al., 1981; Hamnett et al., 1981), it appears appropriate to discuss the chemical reliability of our assay in more detail. Formation of $\mathrm{JH}$-diols by acid catalyzed hydration poses problems when the reaction is carried out with small amounts of $\mathrm{JH}$, i.e. in the nanogram range (Schooley, 1977). In that case it is more advisable to open the epoxide by acid catalyzed methanolysis which yields the corresponding methoxyhydrins. Under the conditions employed here $(200 \mu \mathrm{g}$ $\mathrm{JH}$ ), acid catalyzed hydration proceeds cleanly and in high yield. Stereochemically it is important that this reaction results in approx $97 \%$ inversion at $\mathrm{C}-11$ and $3 \%$ inversion at C-10 (Nakanishi et al., 1971). The
$(+)$-MTPA-derivatives are formed in high yield and the absolute configuration of the diastereomers is well established: on a silica column, the diastereomers of both, JH-I and JH-III elute in the order (10R) before $(10 S)$. However, the distribution of radioactivity in the diastereomers is not precisely the same as in the enatiomers: in addition to the small decrease in optical purity due to inversion at C-10, there may be a small kinetic discrimination between enantiomers in the acylation reaction due to differences in the energies of the diastereomeric transition states. In particular the latter fact may pose serious problems when the chemical yield of the reaction with an optically active acylating reagent is small. We have tested the reliability of the configurational assay by subjecting optically active [methoxy $\left.{ }^{3} \mathrm{H}\right] \mathrm{JH}-\mathrm{I}$ which had been prepared enzymatically by a homogenate of male Hyalophora cecropia acessory sex glands (Peter et al., $1979 \mathrm{~b} ; 1981)$, as well as racemic $\left[10-{ }^{3} \mathrm{H}\right] \mathrm{JH}$-III to the derivatization procedure. The distribution of radioactivity was $96 \pm 2 \%$ (range of values from three analysis) in the (10R)-MTPA-diastereomer of [methoxy- ${ }^{3} \mathrm{H}$ ]JH-I, and $53 \pm 1 \%$ (range of values from three analysis) in the (10R)-MTPA-diastereomer of $\left[10-{ }^{3} \mathrm{H}\right] \mathrm{JH}-\mathrm{III}$. Thus, the deviation in distribution of radioactivity in the diastereomers from that in the original $\mathrm{JH}$-enantiomers is not larger than $\pm 5 \%$. It is difficult to give a precise calculation, since the effects of loss of optical purity due to inversion at C-10 and of kinetic discrimination between the diolenantiomers are additive and affect the relative amounts of diastereomers, depending on the optical purity of JH-sample as well as on the absolute configuration of the JH-enantiomer being in excess.

The results of the present study clearly establish the existence of a $\mathrm{JH}$-III specific binding protein in the haemolymph of adult Colorado potato beetles. The properties of this binding protein are summarized as follows: (1) It has a high molecular weight (mol. wt $>200,000$ ). (2) It has a high affinity for JH-III $\left(K_{\mathrm{d}}=1.3 \pm 0.2 \times 10^{-7} \mathrm{M}\right.$, as determined with the racemate), but binds JH-I less effectively. (3) Consequently it protects JH-III more efficiently than JH-I against degradation by "JH-specific" esterases. (4) It binds the natural (10R)-enantiomer of racemic JH-III with a higher affinity than the unnatural (10S)enantiomer. (5) It does not bind JH-III-diol or JHIII-acid, the main degradation products of JH-III. (6) The concentration of the binding protein in the haemolymph of 4-day old short-day beetles can be calculated from the Scatchard plot and is approx $3 \times 10^{-5} \mathbf{M}$ (see however: Klotz, 1982). From the haemolymph JH (de Kort et al., 1982) concentration, the concentration of the binding protein and the affinity constant one can infer that at $0^{\circ} \mathrm{C}$ over $99^{\circ} \%$ of JH-III is bound to haemolymph proteins.

A JH-III specific binding protein has also been described to occur in haemolymph of adult Locusta migratoria (Peter et al., 1979a). It protects the natural enantiomer of JH-III but not of JH-I against degradation and it has a high molecular weight. Its affinity constant was determined with racemic JH-I only and found to be $K_{\mathrm{d}}=0.8 \times 10^{-8} \mathrm{M}$ (Gellissen, 1978). Recently, Koeppe et al. (1981) described a high affinity carrierprotein $\left(K_{\mathrm{d}}=2 \times 10^{-8} \mathrm{M}\right)$ in the haemolymph of the cockroach, Leucophaea maderae. 
They demonstrated a higher affinity for JH-III than for JH-I, whereas JH-III-acid did not bind to the carrier. Data on the molecular weight of this high affinity binding protein are not available. Since JHIII seems to be the most common juvenile hormone in insects, more work is necessary to test the occurrence of this type of binding protein in other species, in particular during larval stages when much lower levels of $\mathrm{JH}$ are present than in adults (de Kort et al., 1982).

The binding protein for $\mathrm{JH}$ isolated from the haemolymph of larval tobacco hornworm, Manduca sexta, has been well characterized (see Peterson et al., 1982, and references cited there). This single chain polypeptide with a molecular weight of 28,000 binds 1 molecule of JH-I with an affinity constant about $10^{-7} \mathrm{M}$ at $0 \mathrm{C}$ for racemic $\mathrm{JH}-\mathrm{I}$. It has a higher affinity for JH-I and JH-II than for JH-III. It does not bind $\mathrm{JH}$-diol or $\mathrm{JH}$-acid, the two main degradation products of $\mathrm{JH}$. The binding protein protects JH-I against degradation by carboxylesterases, but it is not effective in the presence of $\mathrm{JH}$-specific estereases, which appear only in the last larval instar (Sanburg et al., 1975). Indeed, in larval instars of Manduca sexta $\mathrm{JH}-\mathrm{I}$ and $\mathrm{JH}-\mathrm{II}$ have been shown to be the principal juvenile hormones (Peter et al. 1976; Schooley et al., 1976). A low molecular weight binding protein has been demonstrated in a number of other insect species, but data about the nature and titre of the circulating hormones are lacking (for review see: de Kort and Granger, 1981).

In the Colorado potato beetle JH-III appears to be the only JH present. The titre of JH-III in reproducing adults is at least one order of magnitude higher than that of JH-I and JH-II in larvae of Manduca sexta (de Kort et al., 1982). Moreover, haemolymph from the Colorado beetle contains $\mathrm{JH}$ specific esterases, whose activities are high compared with a number of other adult insects (de Kort et al., 1978; 1979), whereas general carboxylesterases do not contribute significantly to $\mathbf{J H}$ degradation (Kramer and de Kort, 1976). Therefore, the necessity to bind and protect JH-III specifically is greater in the Colorado potato beetle than in Lepidopteran insects. Indeed JH-III appeared to be more effective than $\mathrm{JH}-\mathrm{I}$ in inducing oviposition in short-day animals (Khan et al., 1982).

It thus appears from the comparative analysis of $\mathrm{JH}$ binding proteins that, during the evolution of insects, the nature and titres of juvenile hormones were correlated with the specificity of their binding proteins.

The results described in this paper differ from those previously reported (Kramer and de Kort, 1978), mainly due to the use of JH-I in the earlier study, which was the only radiolabelled $\mathrm{JH}$ available at that time.

Under physiological conditions almost all JH-III is bound to the binding proteins. Therefore, protection against $\mathrm{JH}$-specific esterases seems to be the most likely function of this protein in the Colorado potato beetle. Indeed, our results demonstrated that the natural enantiomer of JH-III can be protected by the protein, but further investigations are necessary to establish the exact mechanism of binding and the molecular characteristics of the binding protein.
Acknowledgement-We thank Dr M. A. Khan for critically reading the manuscript, and the financial support from the Deutsche Forschungsgemeinschaft (grant No. Pe 264/2-2).

\section{REFERENCES}

Feyereisen R., Pratt G. E., Hamnett A. F. (1981) Enzymic synthesis of juvenile hormone in locust corpora allata: evidence for a microsomal cytochrome P-450 linked methyl farnesoate epoxidase. Eur. J. Biochem. 118, 231-238.

Gellissen G. (1978) Isolation und Charakterisierung von drei Proteinen und ihre Bedeutung für die Vitellogenese bei Locusta migratoria. PhD Thesis. Technische Hochschule Darmstadt.

Goodman W.. Schooley D. A. and Gilbert L. I. (1978) Specificity of the juvenile hormone binding protein: the geometrical isomers of juvenile hormone I. Proc. natn. Acad. Sci. U.S.A. 75, 185-189.

Hamnett A. F.. Pratt G. E., Stott K. M., Jennings R. C. (1981) The use of radio HRLC in the identification of the natural substrate of the $O$-methyltransferase and substrate utilization by the enzyme. In: Juvenile Hormone Biochemistry (Ed. by Pratt G. E. and Brooks G. T.) pp. 93-105. Elsevier, Amsterdam.

Khan M. A., Koopmanschap A. B., de Kort C. A. D. (1982) The effects of juvenile hormone, 20-hydroxyecdysone and precocene II on activity of corpora allata and the mode of negative feed back regulation of these glands in the adult Colorado beetle. J. Insect Physiol. 28, 995-1002.

Klotz J. M. (1982) Numbers of receptor sites from Scalchard graphs: Facts and Fantasies. Science 217, $1247-1249$

Koeppe J. K.. Kovalick G. E., Lapointe M. C. (1981) Juvenile hormone interactions with ovarian tissue in Leucophaea maderae. In: Juvenile Hormone Biochemistry (Ed. by Pratt G. E. and Brooks G. T.) pp. 215-23i. Elsevier/North-Holland Biomed., Amsterdam.

de Kort C. A. D. (1969) Hormones and the structural and biochemical properties of the flight muscles in the Colorado beetle. Med. Landhouwhogeschool, Wageningen. 69-2, 1-63.

de Kort C. A. D., Bergot B. J., Schooley D. A. (1982) The nature and titre of juvenile hormone in the Colorado potato beetle, Leptinotarsa decemlineata. J. Insect Physiol. 28, 471-474.

de Kort C. A. D., Granger N. A. (1981) Regulation of the juvenile hormone titre. A. Rev. Ent. 26, 1-26.

de Kort C. A. D., Kramer S. J.. Wieten M. (1978) Regulation of juvenile hormone titres in the adult Colorado beetle: interaction with carboxylesterases and carrierporteins. In: Comparative Endocrinology (Ed. by Gaillard P. J. and Boer H. H.) pp. 507-510. Elsevier/NorthHolland Biomed. Press, Amsterdam.

de Kort C. A. D., Wieten M., Kramer S. J. (1979) The occurrence of juvenile hormone specific esterases in insects. A comparative study. Proc. K. Ned. Akad. Wet. Ser. C. 82, 325-331.

Kramer K. J., Dunn P. E., Peterson R. C., Law J. H. (1976) Interaction of juvenile hormone with binding proteins in insect hemolymph. In: The Juvenile Hormones. (Ed. by Gilbert L. I.) pp. 327-341. Plenum Press. New York.

Kramer S. J., de Kort C. A. D. (1976) Some properties of haemolymph esterases from Leptinotarsa decemlineata Say. Life Sci. 19, 211-218.

Kramer S. J., de Kort C. A. D. (1978) Juvenile hormone carrier lipoproteins in the haemolymph of the Colorado potato beetle, Leptinotarsa decemlineata. Insect Biochem. 8, 87-92.

Nakanishi K., Schooley D. A.. Koreeda M., Dillon J. (1971) Absolute configuration of the $C_{1 \times}$ juvenile hormone: 
application of a new circular dichroism method using tris(dipivaloylmethanato)praeseodymium. J. chem. Soc. Chem. Commun. 1971, 1235-1236.

Peter M. G., Dahm K. H. (1975) Biosynthesis of juvenile hormone in the Cecropia moth. Labelling pattern from $\left[1-{ }^{14} \mathrm{C}\right]$ propionate through degradation to single carbon atom derivatives. Helv. chim. Acta 58, 1037-1048.

Peter M. G., Dahm K. H., Roller H., (1976) The juvenile hormones in blood of larvae and adults of Manduca sexta (Joh.), Z. Naturforsch. 31C, 129-131.

Peter M. G., Gunawan S., Gellissen G., Emmerich H. (1979a) Differences in hydrolysis and binding of homologous juvenile hormones in Locusta migratoria haemolymph. Z. Naturforsch. 34C, 588-598.

Peter M. G., Gunawan S., Emmerich H. (1979b) Preparation of optically pure juvenile hormone I labelled in the ester methyl group with tritium at very high specific activity. Experientia 12, 1141-1142.

Peter M. G., Shirk P. D., Dahm K. H., Roller H. (1981) On the specificity of juvenile hormone biosynthesis in the male Cecropia moth. Z. Naturforsch. 36C, 579-585.

Peterson R. C., Dunn P. E., Seballos H. L., Barbeau B. K., Keim P. S., Riley C. T., Heinrickson R. L., Law J. H. (1982) Juvenile hormone carrier protein of Manduca sexta haemolymph. Improved purification procedure, protein modification studies and sequence of the amino terminus of the protein. Insect Biochem. 12, 643-650.

Sanburg L. L., Kramer K. J., Kezdy F. J. and Law J. H.
(1975) Juvenile hormone-specific esterases in the haemolymph of the tobacco hornworm, Manduca sexta. $J$ Insect Physiol. 21, 873-887.

Schooley D. A. (1977) Analysis of the naturally occurring juvenile hormones - their isolation, identification, and titer determination at physiological levels. In: Analytical Biochemistry of Insects. (Ed. by Turner R. B.) pp. 241-287 Elsevier, Amsterdam.

Schooley D. A., Bergot B. J., Goodman W., Gilbert L. I (1978) Synthesis of both optical isomers of insect juvenile hormone III and their affinity for the juvenile hormonespecific binding protein of Manduca sexta. Biochem. biophys. Res. Commun. 81, 743-749.

Schooley D. A., Judy K. J., Bergot B. J., Hall M. S., Jennings R. C. (1976) Determination of the physiological levels of juvenile hormones in several insects and biosynthesis of the carbon skeletons of the juvenile hormones. In: The Juvenile Hormone. (Ed. by Gilbert L. I.) pp. 101-117. Plenum Press, New York.

Strambi C. Strambi A., DeReggi M. L., Hirn M. H., Delaage M. A. (1981) Radioimmunoassay of insect juvenile hormones and of their diol derivatives. Eur. $J$. Biochem. 118, 401-406.

Weaver R. J., Pratt G. E., Hammett A. F., Jennings R. C (1980) The influence of incubation conditions on the rates of juvenile hormone biosynthesis by corpora allata isolated from adult females of the beetle, Tenebrio molitor. Insect Biochem. 10, 245-254. 